\title{
COMPARISONS BETWEEN AND COMBINATIONS OF DIFFERENT APPROACHES TO ACCELERATE ENGINEERING PROJECTS
}

\author{
H. Steyn \\ Department of Engineering and Technology Management \\ University of Pretoria, South Africa \\ herman.steyn@eng.up.ac.za
}

\begin{abstract}
In this article, traditional project management methods such as PERT and CPM, as well as fast-tracking and systems approaches, viz. concurrent engineering and critical chain, are reviewed with specific reference to their contribution to reducing the duration of the execution phase of engineering projects. Each of these techniques has some role to play in the acceleration of project execution. Combinations of approaches are evaluated by considering the potential of sets consisting of two different approaches each. While PERT and CPM approaches have been combined for many years in a technique called PERT/CPM, new combinations of approaches are discussed. Certain assumptions inherent to PERT and often wrong are not made by the critical chain approach.
\end{abstract}

\section{OPSOMMING}

In hierdie artikel word tradisionele projekbestuurbenaderings soos PERT en CPM asook projekversnelling en stelselbenaderings, naamlik gelyktydige ingenieurswese, en kritiekeketting-ondersoek met betrekking tot die bydrae wat elk tot die versnelling van die uitvoeringsfase van ingenieursprojekte kan lewer. Elk van hierdie benaderings kan ' $n$ spesifieke bydrae tot die versnelling van projekte lewer. Kombinasies, elk bestaande uit twee verskillende benaderings, word geëvalueer. Terwyl PERT en CPM reeds baie jare lank in kombinasie gebruik word, word nuwe kombinasies ook hier bespreek. Sekere aannames inherent aan die PERT-benadering is dikwels foutief. Hierdie aannames word nie deur die kritieke-ketting-benadering gemaak nie. 


\section{INTRODUCTION}

Executing projects fast normally makes financial sense: project execution costs money while financial gain for the shareholders normally materialises only once the project has been completed and the final product has been delivered. In the highly competitive global economy, the speed of project execution is becoming increasingly important to ensure the competitiveness of companies. In many cases, therefore, the faster a project can be completed, the better. The following case illustrates this point: the construction of a plant for the production of a commodity with a highly cyclical demand was timed in such a way that the plant would start production during an upswing in the commodity cycle. However, the project took longer than planned and when it started producing the commodity, the commodity price was much lower than the price assumed in the feasibility studies. This resulted in major losses to the shareholders. Not only project duration, but also a reliable prediction of the completion date, was essential for success.

Furthermore, costs often escalate as a result of extended duration. Certain authors believe that, when the duration of a project with a fixed scope increases, costs usually also increase [1]. One of the reasons for this escalation is that overhead costs normally increase with time, regardless of progress.

One intuitively feels that compressing project duration could increase project risk and, as will be indicated later on in this article, certain methods of expediting projects do in fact increase risks. The benefits of doing projects faster should, therefore, outweigh any risk caused by the acceleration. Approaches that would enable duration compression without increasing business risk would provide several benefits.

This article focuses on different approaches to reduce the duration of engineering projects. First, a number of approaches to project management - with specific reference to the potential of each to reduce the duration of engineering projects - are discussed. Then the potential for integrating the different approaches is addressed.

\section{THE CRITICAL PATH METHOD (CPM)}

The chemical company DuPont, Inc. developed the Critical Path Method (CPM) in the 1950s and this approach was researched well in the 1960s and 1970s. CPM trades off duration compression against additional cost and provides alternative plans: plans of shorter duration although at higher cost and ones at lower cost but of longer duration [2]. Refinements of this technique have been attempted over the past three decades, but there is little evidence of practical application. For the purposes of this article, only the well-established traditional method is considered.

The principle is as follows: opportunities to reduce the duration of activities on the critical path often exist, and such opportunities often incur additional expense. For example, more sophisticated equipment might be employed to complete a task faster and such equipment might cost more per unit of work completed. Where opportunities exist to expedite (or "crash") activities on the critical path by spending more money, two alternatives are presented, namely a normal duration at normal cost and a "crash" duration at a "crash" (higher) cost. The cost slope of an activity is defined as (crash cost - normal cost)/(crash time - normal time). If a number of such opportunities exist for activities on the critical path, it makes sense to crash the ones with the least steep cost slope first. This method enables 
executives to trade off the increase in cost against the benefits of completing the project earlier, and to choose from two or more alternative project schedules with corresponding budgets.

By crashing activities on the critical path, this path becomes shorter relative to the non-critical paths. This means that non-critical paths now have less slack (float) and some of them might also become critical. An increase in the number of critical paths increases the risk of a delay. Reduction of the amount of slack on paths that do not become critical also increases the risk of a delay. The only way to overcome this would be to spend even more money to reduce the duration of non-critical activities as well. This is normally not done and textbooks seem to ignore the increase in risk instead. Furthermore, there are obvious limits to resources that might be utilised on a project.

Crashing does not always produce a viable alternative [3]. Although crashing implies higher risks, more demands on skilled people and significantly higher costs, CPM is, in certain cases, useful to provide executives with alternative project plans.

\section{FAST-TRACKING}

A decision to compress a project schedule by simply overlapping activities that would normally be done in sequence is called "fast-tracking" [3]. Fast-tracking normally implies increased risk, specifically the risk of not meeting specifications without rework. Examples include work started on construction before the design has been completed, manufacturing of a product that has not yet been thoroughly tested or developing a product before a new technology - that will be used in the design - has been proved. As a result of the increase in risk, fast-tracking often does not pay off. It is imperative that initial work such as feasibility studies and project planning receive all the attention necessary before project execution commences. Where decisions are made to fast-track activities, risks are often increased to unacceptable levels.

\section{CONCURRENT ENGINEERING}

Concurrent engineering (CE) offers better opportunities than fast-tracking. While fasttracking simply implies overlapping of activities, CE is a design philosophy of crossfunctional cooperation. Advocates of this method claim that it creates products that are better, cheaper, and more quickly brought to market [4]. It involves a blend of the quality management approach and involvement of people from different functional backgrounds in a design team. According to Gardiner [5], CE has only been in existence as a recognisable topic since the mid 1980s. He quotes a definition from the US Institute for Defence Analysis [6]: "Concurrent engineering is a systematic approach to the integrated, concurrent design of products and their related processes, including manufacture and support. This approach is intended to cause the developers, from the outset, to consider all elements of the product lifecycle from concept through disposal, including quality, cost, schedule and user requirements." Gunasekaran [7] defines $\mathrm{CE}$ as a systematic approach to the integrated, simultaneous design of both products and their related processes such as production. CE has three elements; first, as the name implies, the various activities run concurrently. Secondly, a multidisciplinary project team carries out the activities. All disciplines such as design, test, manufacturing (or construction) and support are involved at all project stages, though the 
level of effort of a specific discipline typically dominates a specific stage. A third vital element is a strong focus on total satisfaction of stakeholders $[8,9]$.

The use of multidisciplinary teams implies, for example, that the team tasked to do the detail design and construction of a plant, should have been involved during the concept design phase. Likewise, members of the team that will operate the plant should be involved in the planning and design phases of the project. This should lead to improved communication that could have a positive effect on project risk.

A number of claims are made by advocates of $\mathrm{CE}$ : Cook [10] claims that, if $\mathrm{CE}$ is implemented intelligently, it should be possible to reduce time to market by $40 \%$ to $50 \%$. CE could improve quality while cutting costs at the same time and it would lead to a product with a more robust specification, design and implementation [11]. Burrows [12] mentions the benefits of a "quality corporate culture", free-flowing information, the systematic dismantling of barriers within the organisation, employee motivation and satisfaction.

Provided that no unrealistic fast-tracking takes place, $\mathrm{CE}$ is helpful in reducing project duration without necessarily increasing risks as a result. $\mathrm{CE}$ might even reduce certain risks.

\section{PERT AND RELATED SIMULATION TECHNIQUES}

\section{The basics of PERT}

As a common misconception is that PERT reduces project duration, this technique justifies some discussion here.

The estimated duration of an activity is by no means fixed: potential exisits for completing the activity either faster or more slowly than the most likely duration. The PERT technique accepts that scheduling is a stochastic problem and takes this variability in the duration of activities into account. Normally the upside potential for early completion is smaller than the downside potential for delay. Consider, for example, the activity of driving to work: it might normally take twenty minutes (realistic estimate) to drive to work but sometimes, due to unforeseen circumstances, it might take much longer. Although the probability of a serious delay, such as might be caused by an accident, is low, it is non-zero. The potential of the activity taking much less than the estimated 20 minutes is rather limited. Thus the downside potential of a possible delay is much greater than the upside potential of finishing the activity faster than in the most likely duration. This implies that the distribution is lognormal as is illustrated in Figure 1.

To simplify calculations, a beta distribution is often assumed [2]. In order to work with three estimated values (minimum, most likely and maximum) and to simplify the problem even further, triangular distribution is quite often assumed. This is a gross oversimplification and results in an underestimate of the effect of risk on project turnout, leading to inappropriate risk management decisions [13].

The three estimated values for activity duration and the Central Limit Theorem are used to estimate probability figures for the duration of the whole project [2]. According to this theorem, if the distribution curves of a relatively large number of independent activities (in this case the activities on the critical path) are summarised, the resulting distribution is 


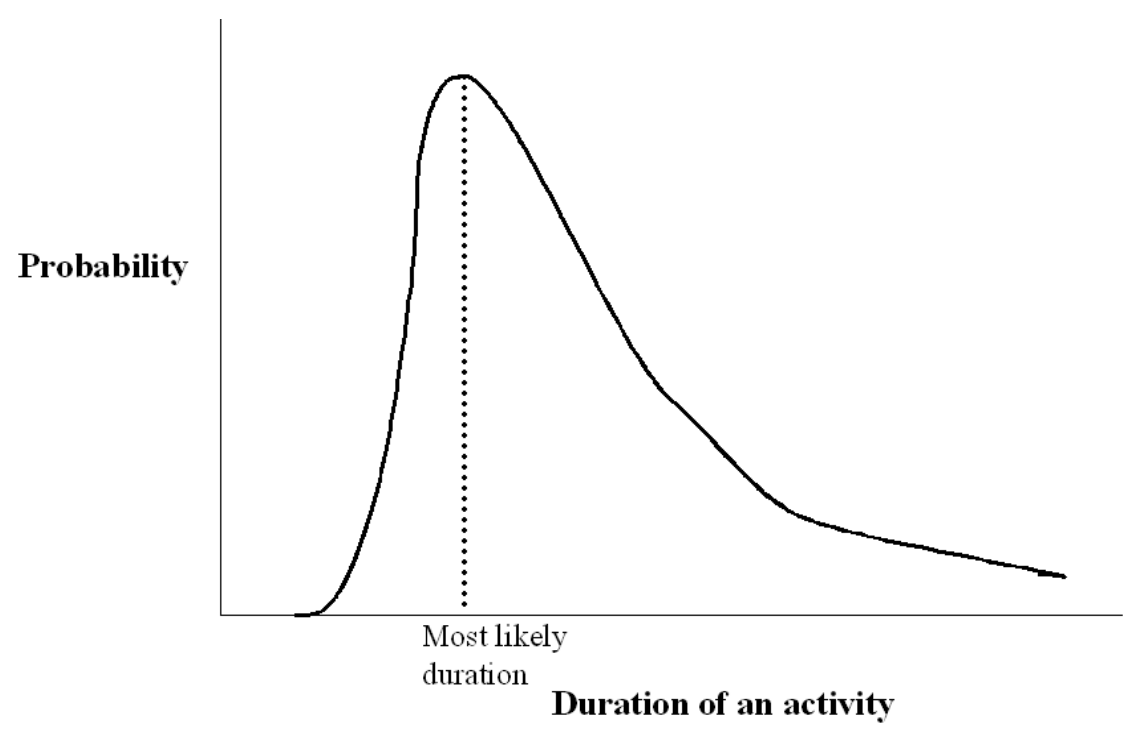

Figure 1. Lognormal distribution of activity duration

normal. Furthermore, for $n$ activities on the critical path, the mean of the distribution of project completion, $\mathrm{E}$, will be given by:

$$
\mathrm{E}=\mathrm{t}_{\mathrm{e} 1}+\mathrm{t}_{\mathrm{e} 2}+\mathrm{t}_{\mathrm{e} 3} \ldots+\mathrm{t}_{\mathrm{en}}
$$

where $t_{\mathrm{ei}}$ is the mean duration of activity $i$. In addition, according to this theorem, the variance of the distribution for project completion, $\mathrm{V}_{\mathrm{T}}$, could be calculated as:

$$
\mathrm{V}_{\mathrm{T}}=\mathrm{V}_{\mathrm{t} 1}+\mathrm{V}_{\mathrm{t} 2}+\mathrm{V}_{\mathrm{t} 3}+\ldots+\mathrm{V}_{\mathrm{tn}}
$$

where $\mathrm{V}_{\mathrm{ti}}$ is the variance associated with activity $i$. With these formulae, given a specific future date, the project manager is in a position to provide a probability figure for completion on or before the specified date. Conversely, given a desired level of confidence, the project manager could calculate a completion date (e.g. for a $90 \%$ level of confidence, the project completion date would be December 2003, but for a $95 \%$ confidence, the project completion date would be February 2004).

\section{Shortcomings}

A first shortcoming is that most applications of PERT do not take into account the so-called "merge point bias" [2]. Merge point bias could be explained as follows: If two paths, each with a $50 \%$ chance of being completed on time, have to be finished before a third activity could start, the probability that the third activity would be able to start on time, is only $25 \%$. If five activities merge (this is typical at the closure stage of many projects) and each activity has a $50 \%$ chance of being completed on time, the probability of the project ending on time is only $(0.5)^{5}$ or approximately $3 \%$. Monte Carlo-type simulation programmes, developed to overcome this shortcoming of PERT, provide information regarding the probability of project duration but do not offer assistance in preventing the delays caused by merge point bias.

The second shortcoming is that the critical path changes from time to time as activities are completed early or fall behind schedule and that PERT does not take into account that noncritical paths might become critical. Simulation programmes take the effect of critical paths 
that become critical into account for the purposes of estimating the end date. The implication is that, during project execution, the project manager does not know what activities are critical and can, therefore, not focus his or her attention on the right activities. The only solution would be to replan frequently - something that few project managers would do.

\section{CRITICAL CHAIN SCHEDULING}

\section{The principle of faster project execution}

A popular explanation of the critical chain approach is given in a novel entitled "Critical Chain" [14]. It is claimed that this approach results in significantly reduced project durations, more accurate and reliable estimates for project completion, as well as in simpler project control.

The critical chain method reduces the complex stochastic problem of variability of activity durations to a deterministic problem through the use of buffers.

The difference between the critical chain and the critical path is that the critical chain already takes into account that a resource can perform one activity only at any given time. When the critical path is determined, a situation of unlimited resources is normally assumed during a first step, and resource levelling is done as a second step.

One of the cornerstones of the critical chain method is the principle of aggregation of contingency reserves $[15,16]$. The principle is simple: if we pool the provision for contingency in project schedules, we need less reserve because some activities will take longer than planned while others will take shorter than planned. As a rule of thumb, activity durations are often halved. The $50 \%$ that has been cut out is placed into a project buffer and this buffer is then cut by $50 \%$. (This is referred to as the " $50 / 50$ " rule or the " $50 \%$ rule"). Although clever scheduling methods such as branch-and-bound could reduce duration further $[17,18]$, aggregation of contingency reserves leads to shorter project durations than methods popularly used in practice.

In order to achieve this aggregation, team members and contractors should not build in any contingency reserve. They should quote only realistic estimates for the duration of their activities. The project manager, however, builds in a reserve (or buffer) to take care of activities taking longer than the realistic estimate, and makes a commitment on the due date of the project.

The project buffer is the first of two buffers that reduce the complex stochastic problem to a relatively simple deterministic one.

\section{Non-critical paths becoming critical and merge point bias}

A second type of buffer is inserted to prevent non-critical paths from becoming critical and thus delaying the project $[1,14,15,19]$. These buffers are called feeding buffers because they are placed where non-critical paths feed into the critical chain. Monitoring of the feeding buffers provides warning signals if a non-critical path is at risk of becoming critical. Feeding buffers reduce the probability that the critical chain would change during project execution. The size of the feeding buffer is obviously of importance. As a result of this stability of the critical chain, the project manager knows what activities are critical, and this enables him or 
her to focus attention where it is needed. Control is simple and the estimated date for project completion is reliable.

Feeding buffers push non-critical paths to an earlier position in the schedule and, provided that they are of sufficient size, eliminate the effect of merge point bias.

\section{Exploiting the opportunities presented by activities done faster than planned}

A mechanism is needed to ensure that, when an activity on the critical chain is completed faster than planned, the successor activity also starts earlier. A third type of buffer, the resource buffer, is introduced [1, 14, 15, 19]. The resource buffer is simply an "early warning", "wake-up call" or "count down" to the start date of the activity. This ensures that the responsible person starts a critical activity as soon as he or she has received all the necessary inputs from preceding activities.

Unlike project management textbooks published before the advent of critical chain in the late 1990s, recently published textbooks such as one by Nicholas [20] and Gray and Larson [21] now suggest the use of buffers.

\section{Criticisms and support}

A number of books, journal papers and other articles have been written about the critical chain method and most of these writings consider critical chain the most important breakthrough in the history of project management and view risk as being pushed into the minority position [17].

The most valid points of criticism come from Herroelen et al [17, 18], who base their comments on simulation experiments. Their points of criticism include the following: They believe that the $50 \%$ rule for buffer sizing leads to serious overestimation of the required buffer protection.

There is always more than one alternative path that could be selected as the critical chain. While most advocates of the critical chain method pick a path at random and provide feeding buffers on the other paths, Herroelen et al $[17,18]$ indicate that it does, in fact, matter which path is chosen. Critical chain schedules created in practice are, therefore, not necessarily optimal. The question arises whether the differences between schedules created by the practitioners and the optimal schedules are significant in practical situations.

Feeding buffers are supposed to eliminate all merge point bias. Herroelen et al $[17,18]$, however, illustrate that cases exist where the delay of a non-critical activity does not only lead to penetration of feeding buffers but also to resource conflicts. This sometimes leads to penetration of the project buffer.

Stability of the critical chain is often seen as a major advantage of the critical chain approach. However, simulation studies done by Herroelen et al $[17,18]$ indicate that regular updating of the schedule (that leads to changes in the critical chain) not only provides the best intermediate estimate of final project duration but also yields the shortest final project duration. They also indicate that the use of clever scheduling and rescheduling mechanisms such as branch-and-bound has a beneficiary effect on the final schedule. 
The author is not aware of any complaints that the above points of criticism put forward by Herroelen et al $[17,18]$ cause problems in practice. The benefits of the refinements that they suggest obviously have to be weighed up against the disadvantage of increased complexity of, for example, Monte Carlo simulations.

\section{TOWARDS INTEGRATION OF APPROACHES}

While the combination of PERT and CPM has been quite common for many years, potential for other combinations of approaches also exists. Combinations of approaches discussed in this article are summarised in Table 1. The combinations are discussed below.

\begin{tabular}{|l|l|l|l|}
\cline { 2 - 4 } \multicolumn{1}{c|}{} & PERT & $\begin{array}{l}\text { Concurrent } \\
\text { Engineering }\end{array}$ & Critical Chain \\
\hline CPM & $\begin{array}{l}\text { Common } \\
\text { practice }\end{array}$ & Supplement each other & $\begin{array}{l}\text { CPM could provide alternative } \\
\text { critical chain schedules }\end{array}$ \\
\hline PERT & Supplement each other & $\begin{array}{l}\text { Limited need for PERT if } \\
\text { critical chain is used }\end{array}$ \\
\hline $\begin{array}{l}\text { Concurrent } \\
\text { Engineering }\end{array}$ & & & Supplement each other \\
\hline
\end{tabular}

Table 1. The potential of different approaches to supplement each other

\section{$C P M$ and $C E$}

$\mathrm{CPM}$ focuses on the project lifecycle and provides alternative plans for a project. It ignores to a large extent the larger system. It does not take into account the effect of a possible delay or expediting of a project on the lifecycle of the project deliverable. For example, if a production plant is delayed, it could cause a reduced market share that is not taken into account. While CPM merely provides a tool to create alternative plans, CE is a systems philosophy that encourages a holistic approach. It stresses, for example, the involvement of all parties for example the simultaneous design of a product, the production system and the product support systems. It also emphasises aspects of teamwork and shareholder satisfaction. CPM and CE supplement each other well and there is no conflict between these approaches. The two approaches can therefore readily be used in combination.

\section{CPM and Critical Chain}

Critical chain strives towards optimisation of the "global" project system rather than any subsystem. This systems approach is used to compress the project duration by managing contingency reserves at a higher level of the system. Once this is done, the schedule could be compressed further by adding additional resources. The CPM tool could then be used to quantify the relationship between this additional cost and the resulting reduction in duration.

Where CPM is used without critical chain principles, the risk of not finishing the project within the scheduled time increases for two reasons:

(a) Additional critical paths are often created.

(b) On paths that remain non-critical, the float is reduced. 
Should CPM and critical chain be combined, the risk associated with reduced float on noncritical paths would be dealt with through feeding buffers, while the project buffer would address the increase in the risk of a delay caused by the increase in the number of critical paths. While CPM crashing increases the risk of a delay, the critical chain approach provides the means to manage this risk.

CPM could, therefore, be used with critical chain to provide alternative critical chain schedules with different durations and budgets. The critical chain principles would reduce the project duration and also provide a more reliable prediction of the due date while CPM would provide information for alternative plans.

\section{PERT and CE}

Like PERT, CPM is a scheduling technique based on quantitative principles, and the "soft" issues addressed by CE could also supplement PERT.

\section{PERT and Critical Chain}

While PERT and critical chain both realise the stochastic nature of the duration of activities, the approaches are very different: PERT is the result of deductive, analytical logic. While it analyses the problem scientifically to provide probabilistic information on project duration, it neglects effects induced by the larger system and inherently makes assumptions that are seldom stated explicitly. Critical chain, on the other hand, also realises the stochastic situation and takes into account the complexities caused by variability that arise when interdependent subsystems interact. The systems approach, that resulted from the theory of constraints, provides contingency reserves at the right level within the systems hierarchy and also takes human behaviour into account. It reduces the complex stochastic problem into a relatively simple deterministic one.

Consider a simple project that consists of only a critical path with five identical activities. The mean duration is 18 days and the standard deviation, $\sigma$, is 4 days (a very high degree of variability is used in this example to illustrate a specific point). Assume we want a very high probability of finishing on time, say, the $3 \sigma$ value.

Critical chain scheduling uses the realistic value of 18 days per activity or 90 days for the project and then adds a project buffer. The Central Limit Theorem could be used to determine the size of the project buffer as follows: The variance for the total project $=V_{\Sigma}$.

$$
\mathrm{V}_{\Sigma}=5 \times 16=80
$$

Therefore, the standard deviation for the project, $\sigma_{\Sigma}$, is $\sqrt{ } 80=8,94$. To ensure high probability of finishing on time, the project buffer should be equal to $3 \sigma_{\Sigma}$. This implies a project duration of 116 days.

A PERT analysis will also indicate that a project duration of 116 days would be required to ensure the same probability of finishing on time. For the PERT analysis, the following assumptions would have been made: 
a) Where contingency reserve has been provided and not utilised, it would not be wasted (work would not expand to fill the time available);

b) Because some activities would take longer than the most likely time while others would take shorter, the effect of activities taking longer than the most likely duration would, to an extent, be offset by activities taking shorter than the most likely durations. This implies that all activities would start immediately once all predecessor activities have been completed. (All resources required would be available immediately upon completion of the predecessors);

c) Non-critical paths would not become critical;

d) Merge-point bias would not play a role.

While these assumptions are made for the PERT analysis, it is no guarantee that they would be valid in practice. Assumption (a) might not be valid because, if each person is expected to make a firm commitment to the duration of his or her activity, they could estimate an activity duration of 30 days in order to ensure a high probability of finishing on time. This would lead to a project duration of 150 days. Once the schedule is fixed at 150 days, it could become a self-fulfilling prophecy. With the critical chain method, the individual responsible for an activity has much less contingency reserve at his or her discretion and is not tempted into wasting contingency reserve.

Assumption (b) might not be valid because resources could be scheduled to start at a specific date and might not be ready to start earlier in the case of a predecessor finishing earlier than planned. With the critical chain method, the resource buffer explained earlier in this article ensures the validity of this assumption.

As discussed earlier, assumptions (c) and (d) are normally not valid but, with the critical chain method, the feeding buffers should ensure the validity of these two assumptions. It is claimed that, with the critical chain method, rescheduling is eliminated to a large extent (although certain authors $[19,20]$ suggest frequent rescheduling in order to obtain optimal results). Furthermore, the resulting stability of the critical chain assists the project manager in focusing his or her attention on the critical activities.

Once a critical chain schedule has been developed, the only use of PERT would be to determine the probability of buffer consumption. When the critical chain approach is used there is, therefore, a very limited need to supplement it with any PERT analysis and the author doubts whether a combination of the two approaches would ever be used in practice.

\section{Concurrent Engineering and Critical Chain}

While both CE and the critical chain method are systems approaches, they address different aspects of project management. Critical chain is, to a large extent, a scheduling approach to managing variability of duration at a higher level within the system than has earlier been the practice, while CE addresses the simultaneous design of the larger system that does not only include the product being developed but also its supporting systems. As in the case of CPM and $\mathrm{CE}$, critical chain and $\mathrm{CE}$ also supplement each other well and there is no conflict 
between these approaches. CE and critical chain could, therefore, readily be combined and should produce good results.

\section{CONCLUSION}

The older quantitative scheduling techniques, PERT and CPM, lack the holism of the more recent systems approaches. Hence the more holistic systems approaches, critical chain and concurrent engineering, add value to traditional scheduling techniques.

Concurrent engineering could be applied regardless of the scheduling tool used. Concurrent engineering and critical chain should be a good combination of techniques to reduce project duration.

Integration of CPM with critical chain should lead to a short project duration and, at the same time, provide cost information regarding plans with alternative durations. CPM, on its own, increases the risks of not meeting the scheduled due date while the combination of CPM and critical chain would address this risk.

When the critical chain approach is used, there is a limited need for PERT analysis.

\section{REFERENCES}

[1] Leach L P, 1999. Critical Chain Project Management improves Project Performance. Project Management Journal", Volume 30 Number 2, pages 39 - 51.

[2] Moder J J, Phillips C R, 1970. "Project Management with CPM and PERT", 2 nd Ed., Van Nostrand Reinhold, New York, 360 pages.

[3] Project Management Institute, 2000. "A guide to the project management body of knowledge", Pennsylvania, USA, 216 pages.

[4] Smith R P, 1997. The historical roots of concurrent engineering fundamentals. "IEEE Transactions on Engineering Management", volume 44, number 1, pages 67-78.

[5] Gardiner G, February 1996. Concurrent and systems engineering: same thing, different name, or are they both just new product introduction?" Engineering Management Journal".

[6] Institute for Defense Analyses (IDA), 1986. Report R-338,

[7] Gunasekaran A, 1998. Concurrent engineering: A competitive strategy for process industries, "The Journal of the Operational Research Society", Oxford, Volume 7, number 9 , pages $758-765$.

[8] Hartley J R, 1992. "Concurrent Engineering”, Productivity Press.

[9] Clausing D P, 1994. "Total Quality Development", ASME Press, New York.

[10] Cook B M, 1991. Design gets a face lift. "Industry Week", volume 240, number 22, page 46.

[11] Novellino J, 1992. Concurrent engineering: another view. "Electronic Design", Volume 40, Number 13, page 18.

[12] Burrows P, 1991. Corporate culture is the next quality frontier (The Culture of Quality). "Electronic Business", volume 17, number 19, page 64.

[13] Graves R, 2001. Open and closed: the Monte Carlo model, "PM Network", volume 15, number 12, pages 48-52. 
[14] Goldratt E M, 1997. "Critical Chain". The North River Press, Great Barrington, MA, 246 pages.

[15] Steyn H, 2001. An investigation into the fundamentals of Critical Chain scheduling. "International Journal of Project Management", volume 19, number 6, pages 363-369.

[16] Steyn H, 2001. Managing contingency reserves in project schedules and budgets. "IEEE International Engineering Management Conference", Albany, New York.

[17] Herroelen W, Leus R, 2001. On the merits and pitfalls of critical chain scheduling. "Journal of Operations Research", volume 19, pages 559- 577.

[18] Herroelen W, Leus R, Demeulemeester E, December 2002. Critical Chain Project Scheduling: Do Not Oversimplify. "Project Management Journal", Volume 33, Number 4 , pages $48-60$.

[19] Newbold R C, 1998. "Project Management in the Fast Lane - Applying the Theory of Constraints", St. Lucie Press, 284 pages.

[20] Nicholas J M, 2001. "Project Management for Business and Technology: Principles and Practice", $2^{\text {nd }}$ Ed. Prentice-Hall, Upper Saddle River, New Jersey, 603 pages.

[21] Gray C F, Larson E W, $2^{\text {nd }}$ Ed. 2002. "Project Management - the managerial process", McGraw-Hill, New York. 574 pages. 